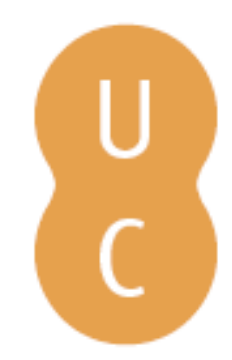

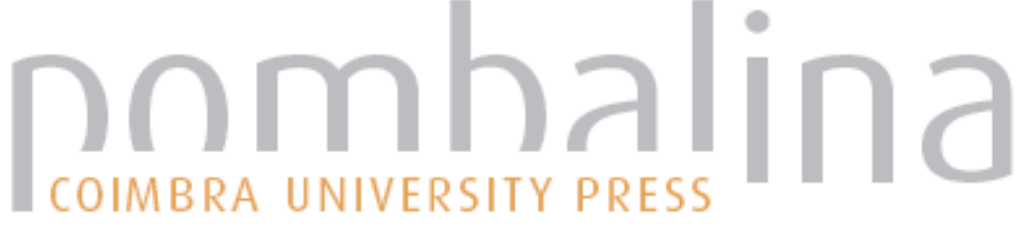

\section{Ensinar com (a História da) arte}

Autor(es): $\quad$ Botto, Maria Isabel Donas

Publicado por: Imprensa da Universidade de Coimbra

URL

persistente: URI:http://hdl.handle.net/10316.2/35914

DOI: $\quad$ DOI:http://dx.doi.org/10.14195/978-989-26-0690-3_4

Accessed : $\quad$ 26-Apr-2023 06:43:58

A navegação consulta e descarregamento dos títulos inseridos nas Bibliotecas Digitais UC Digitalis, UC Pombalina e UC Impactum, pressupõem a aceitação plena e sem reservas dos Termos e Condições de Uso destas Bibliotecas Digitais, disponíveis em https://digitalis.uc.pt/pt-pt/termos.

Conforme exposto nos referidos Termos e Condições de Uso, o descarregamento de títulos de acesso restrito requer uma licença válida de autorização devendo o utilizador aceder ao(s) documento(s) a partir de um endereço de IP da instituição detentora da supramencionada licença.

Ao utilizador é apenas permitido o descarregamento para uso pessoal, pelo que o emprego do(s) título(s) descarregado(s) para outro fim, designadamente comercial, carece de autorização do respetivo autor ou editor da obra.

Na medida em que todas as obras da UC Digitalis se encontram protegidas pelo Código do Direito de Autor e Direitos Conexos e demais legislação aplicável, toda a cópia, parcial ou total, deste documento, nos casos em que é legalmente admitida, deverá conter ou fazer-se acompanhar por este aviso.

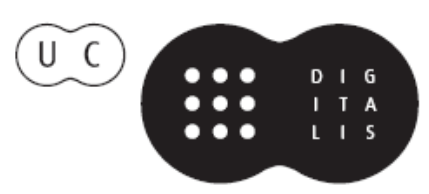




\section{O CRUZAMENTO DE SABERES NA AULA DE INGLÊS}

CONTRIBUTOS PARA UMA PRÁTICA MULTIDISCIPLINAR

ANA R. LUÍS COORD.

IMPRENSA DA UNIVERSIDADE DE COIMBRA COIMBRA UNIVERSITY PRESS 


\section{ENSINAR COM（A HISTÓRIA DA） ARTE}

Maria Isabel Donas Botto

\section{Introdução}

Numa sociedade dominada pela imagem, a defesa da sua utilização na sala de aula poderá parecer redundante. O título deste texto pretende assim esclarecer qualquer dúvida sobre o seu âmbito: trata-se de justificar e exemplificar a utilidade da imagem artística - e mais especificamente, do recurso à história da arte britânica - no ensino da Língua Inglesa.

Não obstante a sua vertente eminentemente prática (pressuposto que exclui, à partida, uma fundamentação teórica mais consolidada do papel das artes no ensino das línguas estrangeiras), o presente artigo integra uma primeira parte onde se tecem algumas considerações gerais sobre o papel das artes no processo de aprendizagem da Língua Inglesa. Gerais, porque não se atribui um papel específico à imagem artística; e também porque, entendendo-se a sala de aula como um espaço de cruzamento de saberes e de questionamento, a aprendizagem, enquanto processo de familiarização com a língua, é encarada como um processo cultural no sentido mais lato da palavra, constituindo assim, necessariamente, um processo de alargamento de horizontes. Na segunda parte, são apresentadas algumas sugestões de imagens artísticas para utilização na sala de aula.

\section{As artes no ensino}

As artes plásticas constituem um meio privilegiado de (a)perceber o mundo - o seu ordenamento (ou desordenamento) espacial, a sua harmonia ou desarmonia cromática, as suas múltiplas contradições. Numa 
entrevista publicada no portal sobre educação Educare.pt, a vice-presidente da Associação de Professores de Expressão e Comunicação Visual (e membro da International Society for Education Through Art), Teresa Torres Eça, salienta um pressuposto consensual no mundo da educação:

Acredita-se hoje que o conhecimento básico dos indivíduos nas sociedades pós-industriais deve incluir inteligências flexíveis, competências criativas verbais e não verbais, capacidades de pensar criticamente e com imaginação, compreensão intercultural e empatia para com a diversidade cultural.

Teresa Torres Eça realça, na sequência deste pressuposto, que "[a] investigação tem demonstrado que estes atributos pessoais são adquiridos através do processo da aprendizagem e utilização de linguagens artísticas.”1

Ainda na mesma tónica, num White Paper recente da NAEA (National Art Education Associations, nos Estados Unidos) com o significativo título "Learning in a Visual Age", sobre o recurso à arte no ensino básico norte-americano, apresenta-se a educação artística como um meio importante de reforçar, para além das competências básicas ("basic skills") dos alunos, o que se designa por "cognição sofisticada." 2

Muitos dos argumentos em defesa da educação artística per se no ensino geral (básico) que estas intervenções sustentam aplicam-se, em minha opinião, ao recurso à arte enquanto plataforma de aprendizagem de outras matérias - e nomeadamente, como neste caso, do ensino do inglês, como exemplificarei mais adiante.

Em "The Magic of Images: Word and Picture in a Media Age", Paglia (2004) denuncia a incapacidade demonstrada pelo sistema educacional norte-americano de se ajustar às portentosas transformações que os novos meios de informação e comunicação provocaram na sociedade e cultura ocidentais, dominadas pela imagem em movimento:

\footnotetext{
1 Entrevista de Joana Silva Santos a Teresa Torres Eça, em Educare.pt: http://www. educare.pt/educare/Atualidade. Noticia.aspx?contentid=3DCBF269442447E2E04400144F16 FAAE\&opsel=1\&channelid=0, consultado a 20 de Julho de 2011.

${ }^{2}$ Learning in a Visual Age: http://alumniconnections.com/olc/filelib/NAEA/cpages/9004/ Library/NAEA_LVA_09.pdf, consultado a 20 de Julho de 2011.
} 
In the last decade in the US, there has also been a relentless speeding up of editing techniques, using flashing, even blinding, strobe-like effects that make it impossible for the eye to linger over any image or even to fully absorb it ... The visual environment for the young, in short, has become confused, fragmented, and unstable. Students now understand moving but not still images.

Paglia argumenta em favor do retorno à imagem estática, a obra de arte ou artefacto, como meio eficaz de promover uma melhor capacidade reflexiva e discursiva, baseada na possibilidade de contemplar e analisar/ ler a imagem fixa.

Hoje em dia, à medida que a sociedade contemporânea vai sendo colonizada pela imagem em movimento, a noção de literacia visual começa a tornar-se relativamente consensual. E se a imagem artística - estática - pode ser muito eficaz no desenvolvimento das capacidades cognitivas e reflexivas dos alunos, fomentando o pensamento crítico e criativo, revela-se ainda mais interessante do ponto de vista linguístico. Enquanto contraponto da dinâmica incessante que envolve as crianças e os adolescentes num turbilhão de imagens em movimento, revela-se instrumental ao proporcionar a oportunidade de desenvolver a capacidade de expressar o que vêem - a capacidade linguística, nas suas vertentes escrita e oral, as quais estão, como se sabe, seriamente afectadas.

\section{As artes plásticas no ensino do Inglês}

No que concerne ao recurso às artes no ensino do Inglês, penso poder generalizar afirmando que a música e o teatro se destacam enquanto meios auxiliares na sala de aula: pequenas representações (encenação de uma peça geralmente adaptada) e em particular, a técnica designada por "roleplay", são utilizadas com frequência, tal como a música de diversos géneros, sendo relativamente comum a utilização de letras de canções de bandas inglesas ou americanas, em geral muito apreciadas pelos adolescentes. 
Por outro lado, é também indiscutível o recurso às imagens na sala de aula, destacando-se uma utilização intensa deste meio com o objectivo de ilustrar a palavra ou conceito que se pretende ensinar - seja na forma de desenhos ou de fotografias. Os próprios manuais atestam a omnipresença da imagem - fotografias a cores, desenhos, muitas vezes humorísticos, e Banda Desenhada dominam os manuais de Língua Inglesa destinados ao ensino básico e secundário em Portugal.

A imagem ilustra e, nessa medida, facilita a mensagem - o desenho da casa que acompanha a palavra "house" é compreensivelmente útil - e deste exemplo muito básico pode-se extrapolar para contextos mais complexos, recorrendo a outras imagens/figuras, nomeadamente a fotografias.

Contudo, 'imagem' não é necessariamente 'arte'. Neste texto defende-se o recurso à imagem artística por oposição a qualquer outro tipo de imagem ou, chamemos-lhe assim, para destacar o seu objectivo específico, o boneco. O que se propõe é, especificamente, o recurso à história da arte britânica - até ao momento presente - para recolher imagens para a sala de aula de Inglês.

Não sendo especialista na área do ensino da língua, e sem pretender enveredar por métodos de didactização, considero que muitas imagens deste tipo poderiam, com vantagem, ser utilizadas até nos níveis de ensino básico, no que se designa por "picture-generated language work" - ou seja, a utilização da imagem para caracterizar as formas, cores e outras caraterísticas, desenvolvendo assim o vocabulário. É no entanto, e sem dúvida, nos níveis mais avançados, em particular do ensino secundário, que o potencial da imagem artística, manifestamente pouco explorado na aprendizagem da língua estrangeira, talvez por receio de "cansar" ou "aborrecer" os alunos com imagens mais "difíceis", poderá ser mais útil, proporcionando excelentes oportunidades para discussão de variados tópicos, no trabalho prático do Inglês. ${ }^{3}$

3 Vide Ben Goldstein, Working with Images, capítulo 7, onde se apresenta uma proposta interessante de trabalho com imagens artísticas (embora não especificamente britânicas) no ensino do Inglês (CUP, 2008). 
Impõe-se, por isso, uma breve análise da chamada "dimensão sociocultural" dos programas de Inglês do ensino secundário. A diminuição marcada e sistemática das componentes histórica e literária dos programas de Inglês ao longo da última década não incentiva, infelizmente, a exploração das potencialidades da pintura e das artes plásticas em geral enquanto meio privilegiado de abordagem de uma grande variedade de temas culturais. Os programas para o $10 .^{\circ}, 11 .^{\circ}$ e $12 .^{\circ}$ - no segmento designado por "dimensão sociocultural" - apresentam as principais temáticas num discurso pautado por clichés do discurso "político-cultural" contemporâneo. Por exemplo: "É necessário que o jovem aprenda a problematizar as questões relacionadas com a mutabilidade social e aprenda a saber estar, de forma equilibrada, no seio destes elementos em permanente mudança" - a propósito da temática "Os Jovens na Era Global", a abordar no $10 .^{\circ}$ ano. ${ }^{4}$

Sem desejar alongar-me nesta área, importa salientar que os programas actuais do ensino secundário parecem partir do pressuposto de que os jovens apenas se interessam por temas a que de algum modo se sintam directamente ligados - que possam reconhecer como do seu mundo. Por exemplo, no $10 .^{\circ}$, contam-se “O Mundo Tecnológico”, “Os Media e a Comunicação Global” e "Os Jovens na Era Global”. No 11. ", "O Mundo à Nossa Volta", "O Jovem e o Consumo" e "O Mundo do Trabalho"; e no 12. ", “A Língua Inglesa e o Mundo", "Cidadania e Multiculturalismo" e "Democracia na Era Global".

Nota-se uma grande insistência nas generalizações sobre o modo de vida contemporâneo - por exemplo, o já referido tema do "signo da mudança”, que domina o programa do $10 .^{\circ}$ ano, o qual beneficiaria de uma abordagem mais crítica - assim como em temas que, apesar de importantes, correm o risco de ser banalizados, dada a sua omnipresença nos meios de comunicação (multiculturalismo, diálogo com o outro, o consumismo). A (in)formação histórica, praticamente ausente dos pro-

\footnotetext{
${ }^{4}$ Gillian Grace Moreira (coord) et. al, Programa de Inglês, nível de continuação, 10. ${ }^{\circ}$, $11 .^{\circ}$ e $12 .^{\circ}$ anos: www.dgidc.min-edu.pt/data/.../Programas/ingles_10_11_12_cont.pdf, consultado a 4 de Setembro de 2011.
} 
gramas, contribui para alargar os horizontes dos alunos e promove uma melhor compreensão da própria Língua Inglesa, sendo, aliás, uma componente indispensável da tão desejada educação para a cidadania que é repetidamente referida como um dos principais objectivos orientadores do programa de Inglês. 5

A proposta ora apresentada sugere um investimento na história da arte britânica para criar uma abordagem alternativa, mais reflexiva pela sua vertente histórica e cultural, desafiando um discurso já muito banalizado (tanto verbal/textual como iconograficamente) pela ênfase na temática da mudança e da miragem tecnológica, do perigo ecológico ou da imagem Benetton do multiculturalismo. Pretende-se mostrar que vale a pena explorar a história da arte das Ilhas Britânicas e utilizar esse conhecimento para alargar os horizontes dos alunos; e mostrar como a propósito de um quadro, de um edifício, de um artefacto, é possível aprender Inglês numa dimensão cultural alargada, alicerçando a compreensão por parte dos alunos da forma complexa como passado, presente e futuro se entrelaçam na construção de uma cultura.

\section{Algumas propostas de aplicação}

No essencial, apresentam-se em seguida algumas propostas com as quais se incentivam outros modos de explorar temas do contemporâneo (tendo como ponto de partida genérico os chamados "domínios de referência" do programa de Inglês) - sugestões para os/as estagiários/as se aventurarem por caminhos menos trilhados na procura de materiais que possam motivar, instruir e desafiar os alunos, estudando cuidadosamente a didactização desses materiais de acordo com as características das turmas. Incluem-se também algumas sugestões de poemas que poderão revelar-se úteis em conjunto com as imagens.

$5 \mathrm{O}$ texto do programa inclui agora uma breve ressalva, salientando a possibilidade, caso se deseje, de fazer curtas incursões históricas relativamente aos domínios de referência. 


\subsection{Sociedade de consumo}

Um conjunto de imagens que ilustram e/ou satirizam a apetência e o fascínio pelo consumo desde o princípio do século:

- Sala de exposição das porcelanas de Wedgwood, em York Street, Londres, em 1809, uma gravura que ilustra bem a precocidade da apetência pelo consumo em Inglaterra.

- George Cruikshank, "All the World Going to See the Great Exhibition of 1851" e "London in 1851", duas ilustrações do genial caricaturista George Cruikshank para a obra de Henry Mayhew's 1851 or The Adventures of Mr. and Mrs. Sandboys and Family, Who Came Up to London to 'Enjoy Themselves,' and to See the Great Exhibition (1851).

- John Orlando Parry, “A London Street Scene" (1835, Alfred Dunhill Collection), uma aguarela que demonstra como a publicidade começava a dominar as ruas de Londres nos anos 30 do século XIX.

- Richard Hamilton, "Just what is it that makes today's homes so different, so appealing?" (1956, Kunsthalle Tubingen). Esta colagem, que se tornou um dos principais símbolos da Arte Pop, pode, no seu comentário sarcástico à primeira vaga de consumismo do pós-guerra, ser contrabalançado com o famoso comentário do Primeiro-Ministro britânico Harold Macmillan: "Indeed let us be frank about it - most of our people have never had it so good. Go around the country, go to the industrial towns, go to the farms and you will see a state of prosperity such as we have never had in my lifetime - nor indeed in the history of this country." Harold Macmillan, num comício do Partido Conservador em Bradford, em 20 de Julho de 1957. (Childs 1997:69; meu itálico).

\subsection{Visões do outro/sociedade multicultural}

Nesta vasta temática inclui-se um conjunto de imagens (quadros a óleo e gravuras) sobre a questão da exploração humana e em particular 
da escravatura. Em complemento a esta temática específica, sugerem-se dois poemas: um desses poemas é do próprio autor da gravura, o poeta e artista William Blake (1757-1827); o outro, "Dependence, or the Ballad of the Little Black Boy (On Francis Wheatley's Family Group and Negro Boy painted in the 1770s)" da autoria de David Dabydeen, autor contemporâneo de origem guianesa, é uma reflexão amarga e irónica sobre a aparente harmonia e felicidade do quadro familiar de F. Wheatley, escrito do ponto de vista do pequeno escravo negro quase invisível do lado esquerdo da tela:

- Francis Wheatley, "A family group in a landscape", c. 1775 (Tate Gallery).

- J.M.W.Turner, “The Slave Ship”, 1840 (Museum of Fine Arts, Boston).

- William Blake, "A negro hung alive by the ribs to a gallows" (1796) - uma imagem perturbadora que ilustra a violência exercida sobre os escravos negros na colónia holandesa de Suriname. Faz parte de um conjunto de ilustrações da autoria de William Blake para a obra de John Gabriel Stedman, Narrative of a Five-Years' Expedition against the Revolted Negroes of Surinam.

- William Blake, "The Little Black Boy" (1789), poema e ilustração, de Songs of Innocence.

- William Holman Hunt, "The Lantern Makers' Courtship": a street scene in Cairo" (1854-61), que ganha em ser confrontada com fotografias actuais das grandes cidades inglesas multiétnicas.

- William Hogarth, "Heads of Six Servants" (1750-55, Tate Gallery), um retrato muito invulgar numa sociedade profundamente marcada pelas divisões de classe. Os criados são retratados com dignidade e humanidade, desligados dos seus afazeres domésticos.

- Grayson Perry, vencedor do prestigiante e controverso Turner Prize em 2003, tem uma obra vasta e provocadora num meio pouco habitual - a cerâmica. Alguns dos (aparentemente inofensivos) vasos e jarras da sua autoria poderão, dependendo das circunstâncias, estimular o debate sobre alguns dos problemas com que a sociedade britânica se debate na actualidade. Nas palavras deste artista, "I want to 
make something that lives as a beautiful piece of art, but on closer inspection a polemic or ideology will come out of it." ${ }^{6}$

\subsection{O mundo da tecnologia}

Dois exemplos, entre os muitos que é possível encontrar, do fascínio e temor relativamente aos grandes progressos tecnológicos do século XIX e XX. A escultura de Epstein foi originariamente construída em gesso aplicado sobre um verdadeiro martelo pneumático. O ameaçador robot é, em 1913-14, o símbolo de uma nova era, mas tudo iria mudar com a $1 .^{a}$ Guerra Mundial. A escultura tem uma história que vale a pena explorar:

-William Turner, "Rain, Steam and Speed - The Great Western Railway" (1844).

- Jacob Epstein, "The Rock Drill" (1914).

- Os quadros de L.S. Lowry sobre a paisagem industrial britânica proporcionam uma excelente oportunidade para discutir o impacto da industrialização nas cidades britânicas, podendo, por exemplo, ser confrontados com fotografias das cidades contemporâneas e em particular das ruas e bairros das inner cities. Adicionalmente, sugerem-se dois poemas, "Man Lying on a Wall": Homage to L.S. Lowry, de Michael Longley, a propósito de um quadro muito curioso de Lowry justamente intitulado "Man Lying on a Wall" (City Art Gallery \& Museum, Salford), e a letra da canção "Matchstalk Men and Matchstalk Cats and Dogs" (1978), de autoria do duo musical inglês Brian and Michael.

${ }^{6}$ Turner Prize: A Retrospective, 1984 - 2006: http://www.tate.org.uk/whats-on/exhibition/turner-prize-retrospective/exhibition-guide/turner-prize-02-05, consultado a 11 de Junho de 2011. 


\subsection{O mundo do trabalho}

Sobre o mundo do trabalho, há uma grande possibilidade de escolha de obras que fundamentalmente denunciam a exploração laboral na sociedade industrial britânica. Entre as sugestões apresentadas, conta-se mais um poema iluminado de Songs of Innocence, de William Blake, assim como o quadro de Frank Holl que pode ser confrontado com o poema de Thomas Hood, "The Song of the Shirt" (1843), onde se descrevem as terríveis condições de trabalho das costureiras nos meados do século XIX:

- William Blake, "The Chimney Sweeper”, poema e ilustração, de Songs of Innocence (1789) e Songs of Experience (1794).

- Frank Holl, “The Song of the Seamstresses”, 1874.

- Luke Fildes, "Applicants for Admission to a Casual Ward" (1874, Royal Holloway College), um quadro sombrio sobre os desempregados e os sem-abrigo na Inglaterra oitocentista.

- George Cruikshank, “Tremendous Sacrifice!” (caricatura, 1840s), uma sátira feroz e impiedosa à exploração do trabalho que sustentava a rentável indústria textil britânica, é um exemplo - entre inúmeros outros de inegável interesse, neste âmbito - deste genial artista.

\subsection{Culturas, artes e sociedade}

O programa do $12 .^{\circ}$ ano inclui um último tema, "Culturas, artes e sociedade", cujo objectivo é "levar o aluno a problematizar algumas manifestações artísticas que caracterizaram a segunda metade do século XX, no âmbito da literatura, do cinema e da música, de entre outras". Neste campo, a internet oferece grandes possibilidades. Entre os muitos recursos possíveis, recomenda-se a consulta dos websites dos principais museus e galerias britânicos orientados para a arte moderna e contemporânea, assim como aqueles cujo acervo inclui também fotografia, escultura, instalação e artes decorativas, tais como a Tate Modern e Tate Britain, a Saatchi Gallery, o Design Museum, a National Portrait Gallery ou até o 
Victoria and Albert Museum que, apesar de muito frequentemente associado à arte vitoriana e eduardiana, tem um vasto acervo contemporâneo nos múltiplos campos das artes visuais e decorativas. Muitos destes websites incluem não apenas informação sobre as obras em exibição, mas também biografias dos artistas, ligações a outros websites relevantes ou apontamentos fílmicos. Em certos casos, até existe a possibilidade, sempre atractiva para os jovens, de alguma interactividade, nomeadamente a propósito de alguma das suas exposições temporárias.

A título de exemplo, ao procurar informação sobre o artista de rua contemporâneo Banksy no website do Museu Victoria and Albert, encontra-se não apenas dois artigos sobre "street art", mas também uma entrevista a Jon Burgerman, um outro artista britânico pouco convencional que se tem destacado na área da ilustração. O mesmo website faculta pequenos filmes que, entre outros assuntos, apresentam entrevistas a artistas contemporâneos, como por exemplo o ceramista britânico Phil Eglin (1959-).7

Em conclusão, com os recursos actualmente disponibilizados pela internet, o empenhamento neste trabalho de levantamento implica algum dispêndio de tempo, mas o resultado pode ser francamente recompensador para professores e alunos.

\section{Referências}

\subsection{Bibliografia}

DAVID ChILDs. 1997. Britain since 1945: A Political History. London and New York: Routledge.

GoldsteIN, B. 2008. Working with Images. Cambridge: Cambridge University Press. Paglia, C. 2004. The Magic of Images: Word and Picture in a Media Age. Arion, III series, Volume 11, No. 3, 1-22.

7 Phil Eglin: Carving out a future: http://www.vam.ac.uk/channel/things/ceramics/ phil_eglin_irreverent_ceramics/, consultado a 11 de maio de 2013. 


\subsection{Webgrafia}

Learning in a Visual Age. The Critical Importance of Visual Arts Education. Estudo publicado pela National Arts Education Association (USA): http:// alumniconnections.com/olc/filelib/NAEA/cpages/9004/Library/NAEA_LVA_09. pdf, consultado a 20 de Julho de 2011.

PHIL EGLIN, Carving out a future: http://www.vam.ac.uk/channel/things/ceramics/ phil_eglin_irreverent_ceramics/, consultado a 11 de Maio de 2013.

Moreira, G. G. (coord); Moreira, A. A.; Roberto, M.T.; Howcroft, S. J.; Pinto De Almeida, T., Programa de Inglês, nível de continuação, $10{ }^{\circ}, 11 .^{\circ}$ e $12 .^{\circ}$ anos: www.dgidc.min-edu.pt/data/.../Programas/ingles_10_11_12_cont.pdf, consultado a 4 de Setembro de 2011.

TEREsA TORRes EÇA, A aprendizagem pelas artes continua a ser desvalorizada. Entrevista de Joana Silva Santos a Teresa Torres Eça: http://www.educare.pt/ educare/Atualidade.Noticia.aspx?contentid=3DCBF269442447E2E04400144F1 6FAAE\&opsel=1\&channelid=0, consultado a 20 de Julho de 2011.

Turner Prize, A Retrospective, 1984-2006: http://www.tate.org.uk/whats-on/ exhibition/turner-prize-retrospective/exhibition-guide/turner-prize-02-05 